\title{
Power and Responsibility in Environmental Policy Making
}

\author{
Manfred J. Holler*, Wenke Wegner**
}

Received 20 December 2010; Accepted 28 September 2011

\begin{abstract}
Given the challenges facing the world in the field of environmental policy, research on complex interdependencies in world politics and transnational policy-making has intensified. Several institutions have came into existence in response to the increasing concerns about global climate change. This paper analyzes the structure of the parties involved in regulating climate conventions and treaties, and designs instruments for allocating responsibility to them. In order to point out the possibilities of allocating responsibility, the relationship between power and responsibility is examined. By applying power measures, we estimate the impact of the various agents in these contractual or instrumental arrangements taking a priori unions into consideration. We examine the United Nations Framework Convention on Climate Change and the United Nations Convention to Combat Desertification. Depending on the decision topics, developing countries can hold more power and responsibility than developed countries. Both conventions refer to responsibilities of the parties as common but differentiated responsibilities. The primary responsibilities and thus power should fall to the industrial countries which is not reflected in our calculations.
\end{abstract}

Keywords Climate change, environmental policy, collective decision making, responsibility, power

JEL classification D7, C7

\section{Introduction}

Efforts to create an international regime which addresses the problems of global climate change have been under way since 1990. Governments have problems finding policies that concur with the demands of electoral politics and at the same time satisfy the needs for global responsibility. The United Nations Framework Convention on Climate Change (UNFCCC) and the United Nation Convention to Combat Desertification (UNCCD) are responses to the threat of global warming. This paper analyze the status of the parties involved in theses regulating climate conventions and treaties, and designs instruments for allocating responsibility to them.

\footnotetext{
* Universität Hamburg, Institute of SocioEconomics, IAW, Von-Melle-Park 5, D-20146 Hamburg, Germany; Public Choice Research Centre (PCRC), FIN-20014 University of Turku, Finland. Phone +494042838 4458, E-mail: holler@econ.uni-hamburg.de

** Universität Hamburg, Institute of SocioEconomics, Von-Melle-Park 5, D-20146 Hamburg, Germany; Universität Hamburg, CliSAP, Grindelberg 5, D-20144 Hamburg, Germany. Phone: +49 40428384529 , Email: wegner@econ.uni-hamburg.de.
} 
In order to point out the possibilities of allocating responsibility, the relationship between power and responsibility is examined. By applying power measures, we estimate the potential impact of the various agents in these contractual or instrumental arrangements, taking the possibility of a priori unions into consideration. The setbased concept of freedom of choice is combined with the agent-based concept of power (see Holler and Alonso-Meijde 2009 for the design of this project). In a recent paper Braham and van Hees (2009) developed causality measures, based on the NESS concept (necessary element of a sufficient set) and highlighted their formal equivalence to the Public Good Index and the Banzhaf index, respectively. Inasmuch as causality is seen as the primary source of responsibility, this relationship supports the allocation of responsibility by means of power measures (see also Braham 2005). Holler (2007) analysed the relation between the concept of freedom of choice, and the concept of power and responsibility. The standard theory of ranking opportunity sets was elaborated such that the Public Good Index can be applied to evaluate the rankings from the point of view of the decision makers.

This paper makes use of this conceptual framework and discusses responsibility in the collective decision making bodies regulating the climate conventions and treaties referred above. In this study, we consider the possibility of a priori unions within the sets of decision makers. For the UNFCCC the decision rule is unanimity and for the UNCCD there is a two-third majority decision rule. There are equal voting weights. Voting power and responsibility are thus equally distributed amongst the parties to the conventions if we do not conclude a priori unions. We define ten a priori unions and apply corresponding a priori power measures. Depending on the decision topics, developing countries can hold more voting power and therefore more responsibility than developed countries. Both conventions refer to the responsibilities of the parties as common but differentiated. ${ }^{1}$ There are convincing arguments that the primary responsibilities should fall to the industrial countries; a result which is not reflected in our calculations. Goodin (1998) proposed task responsibility that specifies 'whose job it is to see to it that certain things are performed and that certain things are accomplished' (p.150). To accomplish things, however, presupposes that those held responsible, can actually do it. This of course implies a greater share of responsibility to developed countries when it comes to dealing with climate change and its costly implications. It seems that a possible solution for an adequate allocation of responsibility could be a reallocation in power.

The paper is organized as follows. In Section 2 we provide the analytical tools such as simple games, power indices and games with a priori unions. In Section 3 we summarize the relationship of freedom of choice, the concept of power and responsibility. Sections 4 and 5 contain an illustration of the Framework Convention on Climate Change and the Convention to Combat Desertification. Section 6 discusses the results of the power measurements. In Section 7 we define the a priori unions and display the a priori power and responsibility. In Section 8 we discuss the responsibility and power

\footnotetext{
1 The meaning of 'common responsibility' is understood by analogy with some known and accepted concepts like common good, common interest or common concern of humankind. The 'differentiated responsibility' component can be approached from two perspectives, the different contributions to the causes of environmental harm and the different capacities to respond to environmental threats. (Timoshenko 2003)
} 
results and compare them with the definition of responsibility given in the context of the Conventions. Finally, we conclude in Section 9.

\section{Preliminaries}

\subsection{Simple games}

A simple game is a pair $(N, W)$ where $N=\{1, \ldots, n\}$ is a finite set of players and $W$ is a set of subsets of $N$ satisfying:

(i) $\emptyset \notin W, N \in W$, and

(ii) the monotonicity property, i.e., let $T \subseteq N$, then $S \in W \Rightarrow T \in W$ for all $S \subseteq T$.

In a simple game $(N, W)$, a coalition $S \subseteq N$ is winning if $S \in W$ and is losing if $S \notin W$. A winning coalition $S \in W$ is a minimal winning coalition (MWC) if each proper subset $T \subset S$ is a losing coalition. We denote by $M^{W}$ the set of MWC of the simple game $(N, W)$. Given a player $i \in N$ we denote by $M_{i}^{W}$ the set of MWC such that $i$ belongs to, that is, $M_{i}^{W}=\left\{S \in M^{W} / i \in S\right\}$.

A power index is a function $f$ assigning each simple game $(N, W)$ an $n$-dimensional real value vector $f(N, W)$, where the $i$-th component of this vector $f_{i}(N, W)$ is the power of player $i$ in the game $(N, W)$ according to $f$.

\subsection{The Public Good Index}

Based on the assumptions that coalitional values are public goods and only minimal winning coalitions are relevant when it comes to power, the Public Good Index (PGI) proposed by Holler (1982) and formalized in Holler and Packel (1983) assigns power proportional to the number of MWCs a player belongs to. It is assumed that the coalitions that are not MWCs are irrelevant when it comes to measuring power and therefore should not be taken into consideration. That is, other winning coalitions apart from MWCs can form but, as they contain surplus players, hold a potential of free-riding when coalitions determine the production of public goods. Therefore, the PGI focuses on MWCs. Given a simple game $(N, W)$, the PGI assigns to each player $i \in N$ the real number:

$$
\delta_{i}(N, W)=\frac{\left|M_{i}^{W}\right|}{\sum_{j \in N}\left|M_{j}^{W}\right|}, \quad i=1, \ldots, n
$$

This implies $\sum_{i \in N} \delta_{i}(N, W)=1$.

\subsection{Games with a priori unions}

The definition of (1) implies that all MWCs are equally likely and no a priori unions of some members of the decision making body under consideration exist. However, if we take into account the possibility that some players may be more likely to cooperate than the others, the idea of coalition structures is helpful (Owen 1977). 
For a set of players $N$, we will denote by $P(N)$ the set of all partitions of $N$. An element $P=\left\{P_{1}, \ldots, P_{u}\right\} \in P(N)$ is called a coalition structure, that is, a set of nonempty and mutually disjoint subsets of $N$ whose union coincides with $N$. It describes the a priori unions on $N$. We also use $P$ as a mapping assigning each player $i$ the union $P(i) \in P$ of which he is a member. A simple game with a coalition structure is a triple $(N, W, P)$, that is, a set of players $N$, set of winnning coalitions $W$ and a coalition structure $P$ on $N$.

We denote by $\operatorname{SIU}(N)$ the set of simple games with a priori unions and player set $N$. Given such a game, the corresponding quotient game is the simple game $(U, \bar{W})$, where the player set $U=\{1, \ldots, u\}$ represents the unions and $\bar{W}$ is the set of winning coalitions. A coalition $R \subseteq U$ in the quotient game is winning if the coalition of represented unions $\bigcup_{k \in R} P_{k}$ is winning in $(N, W)$. We denote the set of minimal winning coalitions in the quotient game by $M^{\bar{W}}$ and $M_{k}^{\bar{W}}$ describes the set of minimal winning coalitions containing union $k \in U$.

A coalitional power index is a mapping $f$ assigning each simple game with a coalition structure $(N, W, P)$ to an $n$-dimensional real valued vector $f(N, W, P)=$ $\left(f_{1}(N, W, P), \ldots, f_{n}(N, W, P)\right)$.

\subsection{The Public Good Index for a priori unions}

Alonso-Meijide et al. (2010a) introduced two variations of the PGI for a priori unions: the Solidarity PGI and the Owen extended PGI. Both measures consider two levels of negotiation. First, they distribute the power among the a priori unions in accordance with the PGI of the quotient game. On the second level, they assign the power of a union to its members. In this paper, we will analyse our problem in accordance with the Solidarity PGI, and the results of our special case coincide with the results that derive from applying the Owen extended PGI.

The Solidarity PGI $\Upsilon$ allocates the power of an a priori union to its members by assigning each union member equal power, that is for each $i \in P_{k}$

$$
\Upsilon_{i}(N, W, P)=\frac{\left|M_{k}^{\bar{W}}\right|}{\sum_{l \in U}\left|M_{l}^{\bar{W}}\right|} \frac{1}{\left|P_{k}\right|}=\delta_{k}(U, \bar{W}) \frac{1}{\left|P_{k}\right|} .
$$

The first term of the last equality coincides with the PGI of the union $P_{k}$ in the quotient game. The term $1 /\left|P_{k}\right|$ indicates that the payoff for player $i$ is the same as for the other players of the a priori union $P_{k}$. The fact that this term looks like sharing the power is due to normalization that implies $\sum_{i \in N} \Upsilon_{i}(N, W, P)=1$.

Holler and Nohn (2009) introduced another four variations of the PGI for a priori unions. The first one is called the Union PGI. The three other ones are power distributions based on threats. ${ }^{2}$ But as the latter ones also coincide with the Solidarity PGI we only consider the Union PGI and the Solidarity PGI for our calculations below.

The Union PGI $\Lambda$ is as close as possible to the original spirit of the PGI, it is based on the two assumptions that the coalitional value is a public good and only

\footnotetext{
${ }^{2}$ These different approaches take the players' threat power to leave their union into account. For an axiom-
} atization of these measures, see Alonso-Meijide et al. (2010b). 
minimal winning coalitions are relevant. The latter assumption does, however, apply to coalitions being minimal both with respect to the simple game and with respect to the coalition structure. A player's power is hence proportional to the number of minimal winning coalitions his union is a member of in the quotient game, that is,

$$
\Lambda_{i}(N, M, P)=\frac{\left|M_{P(i)}^{\bar{W}}\right|}{\sum_{k}\left|P_{k}\right|\left|M_{P_{k}}^{\bar{W}}\right|}, \quad i=1, \ldots, n .
$$

As with the Solidarity PGI, it is obviously the case that all members of the same union have equal power, that is, the Union PGI satisfies the solidarity property as well.

\section{Freedom of choice, the concept of power and responsibility}

In order to analyse the relationship between the concepts of freedom of choice, power and responsibility, Holler (2007) combines the set-based concept of freedom of choice with the agent-based concept of power. The theory of freedom of choice consists in comparing decision situations given by opportunity sets $Y$ which are subsets of the set of alternatives $X{ }^{3}$ It is strictly set-based and decision-makers have no relevance in this comparison. Hence, no preferences of the individual making the decision need to be taken into account. 4

A basis of the PGI is that each element in $M^{W}$ stands for a different collective good, and the winning coalition that forms will pick one of them. So the elements of the set of minimum winning coalitions will be related to the elements of the opportunity set $X$. Set $X$ describes the set of potential social states. Let us define the sets of social states that a player $i$ controls by $X_{i}$, obviously, $X_{i} \subseteq X$. An individual player $i$ cannot choose an element of $X_{i}$ on his own, unless he is a dictator; instead he needs the support of other coalition members to realize his choice. However, no element of $X_{i}$ can be chosen without $i$ 's approval. So $X_{i}$ represents the set of alternatives that $i$ has control of.

Note that coalitions of $M^{W}$ are called decisive sets. Counting the number of decisive coalitions of which $i$ is a member, one gets a value of the decisiveness of $i$. To normalize these values, one has to divide them by the sum of all values of decisiveness. The vector obtained is equatable to the Public Good Index for player $i$.

This approach connects the players with the opportunity sets and suggests to express the freedom of choice by power as measured by the Public Good Index. As power is a potential, the freedom of choice that is considered in this case is a potential as well. Membership in a coalition can also be interpreted as a proxy for the responsibility of an individual decision maker for the social outcome. Social responsibility is a potential, whereas individual responsibility derives from choices. So, it amounts to more than the adding up of individual responsibility when the Public Good Index is used. When player $i$ has power, he has a potential impact on the social outcome and thus he is socially responsible for it. This may imply that $i$ can do something while others

${ }_{3}$ Pattanaik and Xu (1990) characterize an ordering $R$ on the opportunity sets.

${ }^{4}$ Klemisch-Ahlert (1993) applies a weight function to the alternatives of an opportunity set and defines an ordering $R_{\alpha}$ to deal with the preference problems. 
cannot. Player $i$ is individually responsible when he decides to act, and this action together with the possible actions of the other agents determine the social outcome. Of course players also bear legal and political responsibility. It will be interesting to see whether the responsibility of a single player will change if we consider the possibility of a priori unions. If a priori unions exist, it seems plausible to apply a power measure that takes them into account. But if a union is not part of the MWC that finally forms and picks a social outcome, does it still hold some responsibility for that outcome? If it had the opportunity to form a coalition with some of the unions which are now part of the winning coalition, then it had the potential to force a different social outcome. It seems appropriate that this union bears some responsibility for what happens in society. Or, if a coalition forms which is larger then a MWC, are all of the members equally responsible?

\section{The United Nations Framework Convention on Climate Change}

To see the practical implementation of the above questions and investigate the corresponding power analysis, we introduce and explain the design of two climate convention frameworks. Climate change and thus environmental protection is a big issue. Climate and environmental concerns are public goods. In the previous sections we used the Public Good Index to connect power and responsibility. So the next question to raise is, which of the parties to the Conventions hold responsibility for the social outcome that results and to what extent?

The United Nations Framework Convention on Climate Change (UNFCCC) represents a mixture of many different political and economic interests and many complex scientific issues. Governments nominate their respective representatives to participate and negotiate at the sessions of the Convention. This may include ministers, negotiators, and other parties that Governments consider necessary to achieve their goals.

The UNFCCC was opened for signature at the 1992 United Nations Conference on Environment and Development in Rio de Janeiro, also known as the 'Earth Summit'. The Convention enjoys near universal membership, with 192 member countries having ratified. The main goal of the UNFCCC is to stabilize greenhouse gas concentrations at a level that would prevent dangerous anthropogenic interference with the climate system.

Decision-making within the UNFCCC is done through an unanimity rule. Each member of the UNFCCC has one vote. Regional economic integration organizations, in matters within their competence, have the right to vote with a number of votes equal to the number of their member states which are also parties to the Convention. They are not allowed to exercise their right to vote en bloc if any of their member states choose to vote individually, and vice versa (Rule 41). The voting will normally be by show of hands (Rule 48).

\subsection{Bodies of the Convention}

The Conference of the Parties (COP) is the supreme body of the Convention. All countries that ratified the treaty are represented within this body, which has the highest 
authority. The main responsibility of the COP is to continue stressing the need for measures on an international level concerning climate change. Other responsibilities of the COP include reviewing the implementation of convention decisions and examining the commitments of the parties (i.e. member countries). A key task for the COP is to review the national communications and emission inventories submitted by members. Based on this information, the COP assesses the effects of the measures taken by the parties and the progress being made in achieving the ultimate objective of the Convention. The COP meets every year in Bonn, the seat of the secretariat.

The Subsidiary Body for Scientific and Technological Advice (SBTA) is a supporting body of the COP and advises on scientific, technological and methodological matters. It focusses mainly on promoting the development and transfer of new environmentally-friendly technologies, and conducting technical work to improve the guidelines for preparing national communications and emission inventories. The SBSTA also carries out methodological work in specific areas. Another important supporting function of the SBTA is harmonizing the policy-orientated needs of the COP and the new scientific information from expert sources such as the Intergovernmental Panel on Climate Change (IPCC). It also works closely with other international organizations that are involved in sustainable development.

The Subsidiary Body for Implementation (SBI) is another supporting body of the COP, giving advice on matters concerning the implementation of the Convention. It examines the effectiveness of the Convention by assessing the information in the international communications and emission inventories that are submitted by all parties. The SBI reviews the financial assistance given to non-Annex I parties ${ }^{5}$ for the purpose of helping them implement their Convention commitments, and advices the COP regarding adjustments to the financial mechanism. The SBI also advises the COP on budgetary and administrative matters.

Several expert groups exist under the Convention. The Consultative Group of Experts on National Communications from non-Annex 1 parties helps developing countries prepare national reports on climate change issues. The Least Developed Country Expert Group advises such nations on establishing programmes for adapting to climate change. The Expert Group on Technology Transfer promotes the sharing of environmentally-friendly technology with less-advanced nations.

Partner agencies include the Global Environment Facility (GEF). Since 1991 the GEF funds projects in developing countries which have a positive impact on the climate. Because of their expertise, the GEF also grants loans to poorer countries to help them address the difficulties of climate change. The Intergovernmental Panel on Climate Change provides services to the Convention, although it is not a part of it, through publishing comprehensive reviews every five years on the status of climate change and climate-change science, along with special reports and technical papers on request.

\footnotetext{
${ }_{5}^{5}$ Non-Annex I are all countries that are not listed as Annex I parties. They are mostly developing countries, like for example Cambodia or Ghana. They do not have binding emission reduction targets.
} 


\subsection{Actors in the negotiation process}

The member countries of the Convention take decisions at sessions of the COP. In order to increase their influence, member countries often form alliances during negotiations. The Conference has several groupings representing the concerns of developing countries, least-developed countries, small-island states, Europe (through the European Union), non-European industrialized nations, oil-exporting nations, and nations committed to 'environmental integrity'.

Additionally, there are the 'Observers' which are groups and agencies allowed to attend international meetings. The term 'Observers' is used because, although these swaps can speak at the meetings, they are not allowed to participate in the decisionmaking. Among observers permitted by the Convention are intergovernmental agencies, such as United Nations Development Programme (UNDP), the United Nations Environment Programme (UNEP), the World Meteorological Organization (WMO), the OECD, the International Energy Agency and OPEC. To date, there are over 50 intergovernmental agencies and international organizations attending sessions of the Conference of Parties.

Observers also include a lively crowd of non-governmental organizations (NGOs). These represent business and industrial interests, environmental groups, local governments, research and academic institutes, religious bodies, labour organizations, and population groups such as the representatives of indigenous peoples. In order to be identified as an observer, NGOs must be legally constituted not-for-profit entities, competent in matters related to the Convention. Currently, more than 600 NGOs participate in meetings related to the Convention.

Countries, i.e. their representatives, also get extensive input from other sources, both through official channels and in behind-the-scenes dialogue. This is not surprising, considering that the global climate is facing a major threat-coastlines and even whole countries may disappear-and that billions of dollars are being allocated for programmes and activities. This combination attracts all kinds of groups which attempt to influence the outcome of the Convention.

\section{United Nations Convention to combat desertification}

The second institution we will investigate is the United Nations Convention to Combat Desertification (see Johnson 2006). It aim is to combat desertification and reduce the effects of drought. The UNCCD tries to achieve its goals through national action programs that incorporate long-term strategies supported by international cooperation and partnership arrangements. The UNCCD was established in 1992 at the Earth Summit in Rio de Janeiro. It was adopted in Paris, France, on 17 June 1994, coming into force in December 1996. It is the only international framework set up to address the problem of desertification. Desertification is defined as land degradation in arid, semi-arid and dry sub-humid areas, and these 'drylands' cover approximately $47 \%$ of the Earth's surface, excluding polar and sub-polar areas. 192 parties and the European Community have acceded to the UNCCD as a legally binding framework that helps to provide a comprehensive answer to problems relating to the environment. 
The ultimate objective of the UNCCD is to reduce poverty through improved living conditions and the achievement of sustainable development in areas affected by desertification. The UNCCD interprets the fight against desertification as a multidimensional process that requires action in the fields of policy-making, management of natural resources, and social and economic development. National Action Programmes (NAPs) are the UNCCD's main instruments of implementation in participating countries. In a NAP each affected country defines the priority activities to be undertaken and the roles of various national actors in the implementation of the UNCCD policy. Through the national action program process, the UNCCD places the affected countries in the 'drivers seat'. The developed countries, intergovernmental and non-governmental organizations and other relevant stakeholders are then requested to actively support the implementation of the programs. It therefore establishes a system of shared responsibility, in which the UNCCD parties agree to a set of specific obligations.

Whithin the UNCCD each member party has one vote. Regional economic integration organizations have the right to a vote weighted by the number of votes that equals the number of their member states that are also parties to the Convention. They are not allowed to exercise the right to vote en bloc if any of their member states exercises its right (Rule 46). The parties have to make every effort to reach an unanimous agreement on all matters of substance. If all efforts to reach consensus have been exhausted and no agreement has been reached, the decision will, as a last resort, be taken by a twothirds majority vote of the parties present and voting. Decisions of the COP on matters of procedure have to be taken by a majority vote of the parties present and voting (Rule 47). Voting, except for elections, will normally be by show of hands (Rule 52).

The structure of the UNCCD ist very similar to the one of the UNFCCC. The Conference of the Parties is the supreme body of the Convention. One of its main functions is to review reports submitted by the member states of the Convention detailing how they are carrying out their commitments; the COP makes recommendations on the basis of these reports. The COP is assisted by two subsidiary bodies, the body of the Committee on Science and Technology and the Committee for the Review of the Implementation of the Convention. The COP meet biennally, interchanging with sessions of the Committee for the Review of the Implementation of the Convention.

Under the supervision of the COP the Committee on Science and Technology should make provisions for surveying and evaluating of the relevant existing networks, institutions, and agencies which are interested in becoming a member of the Convention. Another supporting body of the UNCCD is the Committee for the Implementation of the Convention.

\section{Power and responsibility measurement}

As the decision rule for the UNFCCC is an unanimity rule, the a priori voting power and thus the responsibility are equal for each member party. There is just one minimum winning coalition which contains all 192 member parties. Therefore, by symmetry the power is $1 / 192$. The decision rule for the UNCCD is a two-third majority rule on all matters of substance if all efforts to reach consensus have been exhausted. Each of the 
member states has one vote. With 193 parties present and voting 129 votes are required for a decision to pass. The a priori voting power is by symmetry, 1/193.

The difference in the measures is due to total membership numbers. However, regional economic integration organizations have the right to vote with a number of votes equal to the number of their member states if the latter are parties to the Convention. These organizations can vote as a bloc only if none of their member states will vote for itself.

All decisions on the UNFCCC must be adopted by consensus. This is not quite the same as unanimity. Here, the will of the $\mathrm{Chair}^{6}$ and his or her ability to reflect consensus take precedence. For example, the Chair may decide to ignore a party's objection, or a party may choose not to object formally to a decision, but to ask for its concerns to be taken note of in the report on the session.

We calculate the passage probability ${ }^{7}$ by dividing the number of winning coalitions by the number of possible coalitions. For the UNFCCC there is just one possible winning coalition and that is the one containing all the member states. Therefore, the passage probability and thus efficiency is minimal. The assertiveness of new decisions compared to the status quo is minimal in the UNFCCC.

However, the a priori voting power of the members of the UNCCD and UNFCCC is likely to differ if one considers a priori unions and a priori power. As a consequence, responsibility should change as well.

\subsection{A priori unions}

The member parties of the climate change regime (the UNCCD as well as the UNFCCC) are organized into a number of different groups and coalitions. Established practise in the UN system divides UN members into five regional groups: Africa, Asia, Central and Eastern Europe (CEE), Latin America and the Caribbean (GRULAC) and Western Europe and others (WEOG). The fifth group includes Australia, Canada, New Zealand and the United States.

The regional group system is only of limited relevance to the main interests of parties in the climate change negotiations. With the exception of the African Group which also serves as a negotiating coalition, the regional groups are used to nominate candidates to the Bureaux and the specialised bodies only. Most parties belong to political negotiating coalitions, formed on the basis of members' common interests or cultural, economic or geographic affinities. Some are active throughout the intergovernmental arena, while others are specific to the environmental or climate change context. There are a few parties that do not belong to any of these coalitions and some others that are members of several coalitions. There is no formal process for establishing these groups. They meet informally during sessions of the COP or the Subsidiary Bodies. Their purpose is to exchange information on common issues, and, in some instances,

\footnotetext{
6 The chair is elected by the parties to head chair the Committee of the Whole or one of the subsidiary bodies. He is responsible for facilitating progress towards an agreement.

7 Baldwin and Widgrén (2004) refer to the passage probability for measuring the EU's decision making efficiency.
} 
develop and agree to common positions. In the following we introduce the various a priori unions that are (or were) relevant for the voting in the climate conventions.

The European Union (EU) is the most cohesive negotiating coalition in the climate change regime. Its 27 member states plus the European Community (represented by the European Commission) articulate a common position on all issues, almost always speaking with a single voice. ${ }^{8}$

The European Community, represented by the European Commission, has become a party to the Convention as a regional economic integration organization.

Umbrella Group (UG) members share similar values and principles in the climate change negotiations, centered on the dual ambition of flexibility and cost-effectiveness. Their national circumstances and their political engagement, however, are very diverse. This explains why the Umbrella Group is only a loose coalition, which does not always negotiate as a single entity. The Umbrella Group consists of 9 members: Japan, U.S., Canada, Iceland, Australia, New Zealand, Russia, the Ukraine and Norway.

This group developed from the longer standing JUSSCANNZ group. The difference between these two groups is that the Umbrella Group does not include Switzerland but Russia and the Ukraine instead.

The Environmental Integrity Group (EIG) is a group comprising Mexico, the Republic of Korea and Switzerland. It emerged at the thirteenth session of the SBs held in Lyon in September 2000. It aims to achieve environmental integrity in the outcome of climate change negotiations. It is the only group that brings together the non-Annex I parties (Mexico, Republic of Korea) and an Annex I party (Switzerland). All three parties are members of the OECD. Like most other negotiation groups, the EIG develops common positions and feeds them into the climate change process.

A number of countries of Asia and of Central and Eastern Europe, which are not included in Annex I, have joined to form the group Central Asia, Caucasus, Albania and Moldova (CACAM). Although these countries are not included in Annex I, they do not consider themselves to be developing countries and are not members of the G77. They have consequently asked the COP for a clarification of their status under the Convention. However, so far the COP has been unable to take a decision on this matter and will consider it at a future session.

Open Balkan Group (OBG) consist of Bosnia Herzegovina, the Former Yugoslav Republic of Macedonia and Yugoslavia (which has since become Serbia and Montenegro). In 2001 they expressed interest in forming their own negotiating coalition. The countries are Non-Annex I parties but consider themselves to be economies in transition and not developing countries.

The Group of 77 and China (G77) was founded in 1964 by seventy-seven developing countries in the context of the United Nations Conference on Trade and Development, explicitly to counter the power of the developed world. They now function throughout the United Nations system, comprising 130 members. The G77 consists of small island countries, oil-exporting countries, LDCs, industrializing countries, and

\footnotetext{
${ }^{8}$ For our calculation we use a voting weight of 29 for the EU bloc. Estonia is not a member of the UNCCD. Furthermore, we count Turkey and Croatia's vote to the EU bloc as they are in no other a priori union and candidates to join the EU.
} 
middle-income countries. China is exclusively a member of the G77 and not of any subgroup.

While G77 members broadly share common principles, their national circumstances vary considerably. This is reflected by the other groups that act within the G77, such as the African Group, the Alliance of Small Island States and the group of Least Developed Countries. Although the members of the $\mathrm{G} 77$ have increased to 130 countries, the original name was retained because of its historic significance. Here are various subgroups:

(i) The 49 countries defined as Least Developed Countries (LDCs) by the United Nations are also Convention parties. They include Afghanistan, Haiti, Nepal and the Sudan. Some LDCs are also members of the African Group, the Alliance of Small Island States and others. They are increasingly active in the climate change process, often working together to defend their particular interests in, for example, vulnerability and adaptation to climate change.

(ii) The Alliance of Small Island States (AOSIS) is an alliance of 39 (plus 4 observers) small island states and low-lying coastal countries, e.g. Singapore, Saint Lucia and Mauritius. They share similar development challenges and environmental concerns, especially their vulnerability to the adverse effects of global climate change. Most of the AOSIS members also belong to the Small Island Developing States (SIDS).

(iii) The League of Arab States (ARAB) is a regional organization of Arab states in Southwest Asia, and North and Northeast Africa, e.g. Morocco, Lebanon and Bahrain. The Arab League currently has 21 members (plus Palestine). The main goal of the league is to draw closer the relations between member states and to co-ordinate collaboration between them. All members of the League of Arab States are members of the Group of 77.

(iv) As already mentioned, the African Group (AG) is the only regional group working as an active negotiating group. It consists of 53 members, e.g. Angola, Egypt and Ghana. They have common concerns, such as the lack of resources and the vulnerability to extreme climate conditions. The group often makes common statements on various issues, such as capacity-building and technology transfer.

Figure 1 shows the a priori unions inside the Convention and how they are connected. The shaded boxes represent groups that are also active outside the climate change regime in contrast to the unshaded spheres which stand for the groups which are exclusive to the climate change regime.

\subsection{A priori power and responsibility}

We will now compute two a priori versions of the PGI to analyze the UNCCD. It will suffice to focus on this institution because the parties of the UNCCD overlap closely with those of the UNFCCC. Moreover, as the UNFCCC decision making rule is unanimity, the assertiveness of new decisions compared to the status quo is minimal in the UNFCCC. We consider 193 players (member states). If we abstract from a priori 


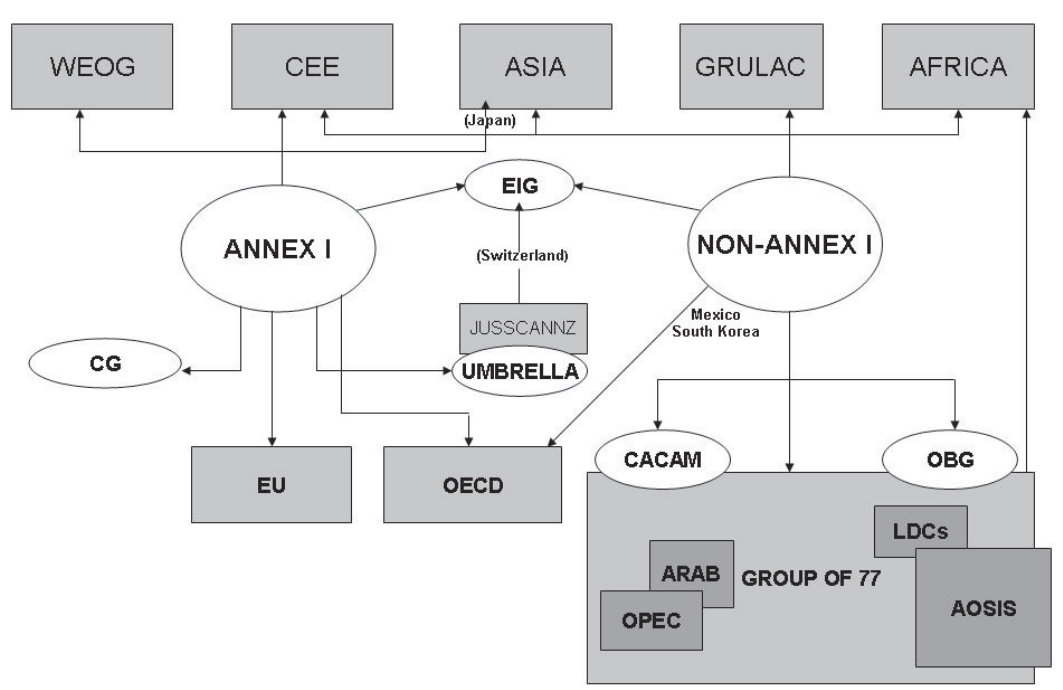

Figure 1. Party Grouping in the International Climate Change Regime (Source: Yamin and Depledge (2004), own alterations)

unions, the UNCCD can be represented as the following weighted two-third majority game:

$$
v=[129: \underbrace{1,1,1, \ldots, 1}_{193}] .
$$

The corresponding set of minimal winning coalitions, $M^{W}$, is obvious.

However, if we take likely a priori unions into account, we may divide the parties of the UNCCD such that the following system of a priori unions applies:

$$
P=\{E U, C A C A M, U G, E I G, L D C, A O S I S, O B G, G 77, A G, A R A B, R o W\}
$$

As there are some member states which are part of more than one a priori union, ${ }^{9}$ there exist many possible weighted combination of a priori unions (i.e. partitions). We examine five of them. The order of the priority of the a priori unions can be justified by their preferences toward a given decision topic. For example, an issue related to the changing sea level could be an fundamental topic to the AOSIS. Countries which are members of the AOSIS as well as of some other a priori union would, in this case, give their vote to the AOSIS. The justification for the dividing line between the a priori unions is that the bottom half are unions which contain countries belong to more than one a priori union and, therefore, the weights of these a priori unions will differ depending on the decision topic. Table 1 shows the alternative partitions $P 1, \ldots, P 5$ and the related voting weights.

\footnotetext{
${ }^{9}$ Most of the G77 members are in more then one negotiating group.
} 
Table 1. A Priori Unions of the UNCCD

\begin{tabular}{lccccc}
\hline & \multicolumn{5}{c}{ Voting weights } \\
A priori union & P1 & P2 & P3 & P4 & P5 \\
\hline European Union (EU) & 29 & 29 & 29 & 29 & 29 \\
CACAM & 7 & 7 & 7 & 7 & 6 \\
Umbrella Group (UG) & 9 & 9 & 9 & 9 & 9 \\
Open Balkan Group (OBG) & 4 & 4 & 4 & 4 & 3 \\
Environmental Integrity Group (EIG) & 3 & 3 & 3 & 3 & 3 \\
\hline Least Developed Countries (LDC) & 38 & 49 & 43 & 16 & 2 \\
Alliance of Small Island States (AOSIS) & 39 & 28 & 28 & 25 & 4 \\
League of Arab States (ARAB) & 14 & 14 & 20 & 9 & 0 \\
African Group (AG) & 12 & 12 & 12 & 53 & 0 \\
Group of 77 (G77) & 29 & 29 & 29 & 29 & 128 \\
Rest of the World (each weight 1) & 9 & 9 & 9 & 9 & 9 \\
\hline & AOSIS & LDC & ARAB & AG & G77 \\
& LDC & AOSIS & LDC & LDC & AG \\
Example of an order of the Unions & ARAB & ARAB & AOSIS & ARAB & LDC \\
Related to the topic of decisions & AG & AG & AG & AOSIS & ARAB \\
& G77 & G77 & G77 & G77 & AOSIS \\
\hline
\end{tabular}

The individual member states of the UNCCD are symmetric, inasmuch as they all have the same voting weights. As a consequence, as already demonstrated in Section 2.4, the Solidarity PGI, the Owen extended PGI and the three power distributions based on threats coincide. Therefore, we focus on the Solidarity PGI and the Union PGI.

In Table 2 we calculated the results of the quotient game of the Solidarity PGI, i.e. the Public Good Index for the different a priori unions with regard to the different weighted systems. For the Solidarity PGI the second step is to devide the assigned union power by the number of members of the respective union.

Table 3 shows some results for selected member countries according to the Solidarity PGI and the Union PGI. In regards to the Solidarity PGI, Germany, as a representative of the EU, holds the same power as India and China which are members of the G77. That can be explained by the fact that there are 19 players ${ }^{10}$ and that the decision rule requires 129 votes, so all a priori unions are almost equally represented in the set of MWC. Lichtenstein as a single player bears most of the power, because it does not share its power inside a union. But this does not seam reasonable since Lichtenstein is a very small country and it stands on its own with no alliance. In regards to the Union PGI, the single player Lichtenstein has less power then most of the other member states. Germany as the EU representative again holds the same power as the G77 members. Depending on the decision topic, and thus on the voting weights, in almost any of the considered cases the developing countries of the AOSIS, LDC or

10 There are 10 unions and 9 single player, see Table 1. 
Table 2. PGI of the unions in the quotient game

\begin{tabular}{lccccc}
\hline & \multicolumn{5}{c}{ UNCCD } \\
& \multicolumn{5}{c}{ Public Good Index } \\
A priori unions & $P 1$ & $P 2$ & $P 3$ & $P 4$ & $P 5$ \\
\hline European Union (EU) & 0.06948 & 0.06237 & 0.06158 & 0.05978 & 0.03125 \\
CACAM & 0.04441 & 0.05136 & 0.05007 & 0.04929 & 0.03125 \\
Umbrella Group (UG) & 0.04743 & 0.04802 & 0.04977 & 0.05687 & 0.03125 \\
Open Balkan Group (OBG) & 0.05216 & 0.05283 & 0.05584 & 0.04313 & 0.03125 \\
Environmental Integrity Group (EIG) & 0.04933 & 0.04761 & 0.04891 & 0.04944 & 0.03125 \\
Least Developed Countries (LDC) & 0.07099 & 0.08111 & 0.07709 & 0.04117 & 0.03125 \\
Alliance of Small Island States (AOSIS) & 0.07185 & 0.06211 & 0.05922 & 0.06094 & 0.03125 \\
League of Arab States (ARAB) & 0.04912 & 0.05046 & 0.05063 & 0.05687 & 0 \\
African Group (AG) & 0.04852 & 0.05198 & 0.05843 & 0.08626 & 0 \\
Group of 77 (G77) & 0.06948 & 0.06237 & 0.06158 & 0.05978 & 0.5 \\
Rest of the World (9 members) & 0.04747 & 0.04775 & 0.04743 & 0.04850 & 0.03125 \\
\hline
\end{tabular}

the G77 hold the most power. Therefore even though Germany or any other EU member holds substantial voting power, in almost every decision case there are developing countries which are more powerful. In the extreme case, where the $P 5$ partition for a priori unions applies, the group of G77 has a 50\% share of the power in the quotient game. One can see that, if power is measured by the Union PGI, the member states of the G77, when voting as a bloc, hold much more voting power than all other states.

\section{Responsibility and the Conventions}

Both, the UNFCCC and the UNCCD, refer to the responsibilities of the parties as 'common but differentiated responsibilities'. Concerning the UNFCCC the shared responsibility of the parties is described as the contribution to the preservation of the global climate system, an obligation which is imposed on them 'for the benefit of present and future generations of humankind' (UNFCCC 2004). This is meant to imply that all the major economic and political players, as well as their citizens and consumers, have a role in implementing the programme.

The differentiated responsibilities of the developed countries, on the one hand, and of the developing countries, on the other, is a distinction based on the principle of equity and the varying capacities of the two categories of country. The primary responsibility which falls to the industrial countries is based on their historic contribution to the increase in Green House Gas concentration in the atmosphere and also on their level of economic potential. The first argument derives from Goodin's 'blame responsibility' while the second constitutes 'task responsibility'. Goodin (1998, p. 150) argues that blame responsibility is backward-looking, and should be shunned for policy purpose but which nonetheless seems to dominate discussions of social welfare (see King 2006 for further discussion). In general, industrial countries also have a better scientific, 


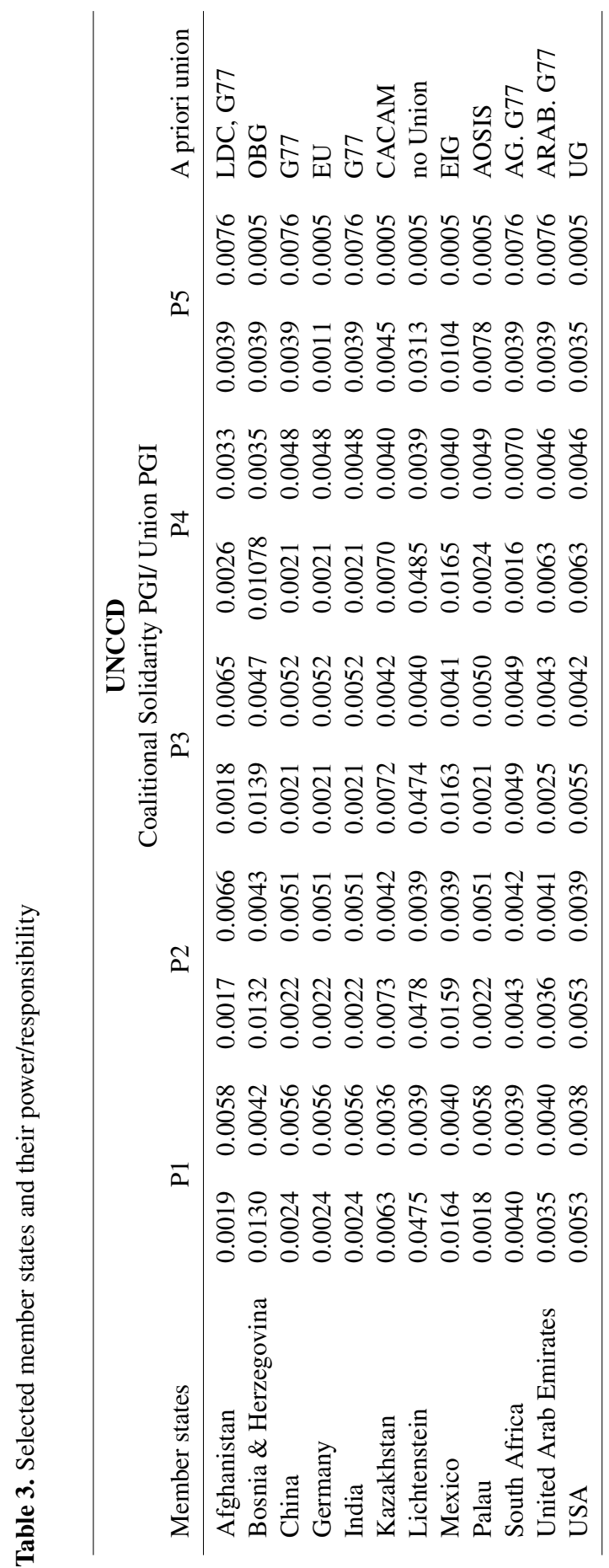


technological and financial capacity than developing countries. The UNFCCC recognizes that reductions by developing countries in their rate of emissions growth will depend on the provision of financial and technical assistance from developed countries. Following this argument, developed countries should be the first to act. While industrialized countries bear a greater historical responsibility, annual emissions from developing countries are expected to start exceeding those of industrialized countries within the next two decades. Yet different countries place very different priorities on the issue and climate change raises complicated issues of equity.

Regarding the UNCCD, the responsibility of the developing countries is combating desertification and mitigating the effects of drought. They are placed in the 'driver's seat'. As defined in Article 6 of the Convention, developed countries once again are called upon to support those countries financially.

The question is, how can we combine this 'differentiated responsibility' definition with the responsibility approach that we deal with in Section 3? Is it that the more developed countries hold part of the responsibility for the developing countries? And is this inequality reflected in voting power? They are obviously wealthier and have better access concerning new technologies and science. If we consider the possibility of a priori unions, power and thus responsibility differs between countries. Looking at the results of Section 6, we may ask the question whether the developed world holds more power and responsibility? Is there a fair allocation of responsibility between developed and developing member states?

The results show that in most of the considered cases developing countries have more voting power than developed countries. The differentiated responsibilities as referred in this section are not consistent with the results of section 6 . Underlying the theory we used in this paper is the assumption that developed countries should have more voting power if they are made more responsible. But what is a fair allocation? Industrialised countries bear more responsibility because of their history. Moreover, they control a larger capacity concerning science and technology. They also provide a larger financial contribution. Therefore, ought they not have a greater influence on what to do with the money, technology and the scientific results? A possible solution for a reasonable allocation of responsibility and power could be a 'shift in power' from the developing countries to the industrial countries. That could be accomplished by a different decision rule or voting weights.

\section{Institutional framing versus ad hoc decision making}

In this paper we analysed the potential impact of the various agents, i.e., the representatives of member countries, in the United Nations Framework Convention on Climate Change (UNFCCC) and the United Nations Convention to Combat Desertification (UNCCD). The stability of the climate and those collective measures designed to react to climate changes were considered public goods, and, therefore, the application of the Public Good Index promised to be a straightforward way to quantify the impact of the agents on the corresponding policies. UNFCCC decision making requires unanimity and the UNCCD relies on a two-third majority rule. Given that 'one country, 
one vote' applies for the UNFCCC and the UNCCD, the power calculation is rather trivial: in both cases, the representatives of individual member countries have equal power, although for different reasons. In the case of UNFCCC, our implicit assumption is that, in the long run, a qualified majority rule will be introduced, quite similar to what we observed in the decision making of the EU Council of Ministers. Our study is meant to be a first step in delivering a framework for such an institutional change. Moreover, if unanimity no longer dominates and there are more or less stable ties between groups of agents such that a priori unions exist, then the decision situation can be described by a non-trivial weighted voting game and the power distribution is not obvious. In order to exemplify the method and to derive first results we have discussed the power problem for the UNCCD under the pretext that a priori unions can be identified.

The underlying assumption of our study is that, in the long run, international environmental policy, including climate change policies, have to be defined and organized by international institutions like UNFCCC and UNCCD and cannot rely on ad-hoc meetings of national governmental representatives who, more or less, want to serve their national clientele by expressive decision making and the issuing of hollow declarations with hardly any consequences. Of course, government representatives are hardly impartial when it comes to making decisions on specific policy measures, as their main responsibility is to their national electorates. Even dictatorial governments have to take care to consider the preferences of their national power base. It is common knowledge that, at least in the short-run, free-riding is the dominant strategy when it comes to the production of public goods like a 'clean environment.' Obviously, the time horizon of elected governments is limited by the re-election constraint. Dictatorial governments do not depend on majorities but in general rely on servicing a political elite that contributes resources and support in exchange for privileges. ${ }^{11}$ Many governments, represented in UNFCCC and UNCCD, can be classified as being located between these poles. In order to circumvent the trap of self-interested national representation and free-riding, decision-making power and the corresponding responsibility, should be assigned behind a veil of ignorance, i.e. allocated to international institutions before the states of nature and the related decision problems are known. Unfortunately, the possible veil of ignorance is already very thin because many problems and their corresponding addressees are known. Moreover, it is highly urgent that the international community implement institutions that can execute political power in climate change policies. Once established, it can be expected that such institutions will extend their activities and influence into those realms which are governed by national self-interest today. The history of the EU shows some evidence for this but also gives alarming examples. ${ }^{12}$ However, we can only expect the necessary transfer of political power from national governments to international institutions if the latter are well defined, their power structure is lucid, and the possible allocation of responsibility is acceptable. This study substantiates some of the related problems.

\footnotetext{
11 See the various contributions in The Rationale of Revolutions, edited by Mario Ferrero (2004).

12 See EU agricultural policy.
} 


\section{References}

Alonso-Meijide, J. M. and Holler, M. J. (2009). Freedom of Choice and Weighted Monotonicity of Power. Metroeconomica, 60(4), 571-583.

Alonso-Meijide, J. M., Casas-Méndez, B., Fiestras-Janeiro, G. and Holler, M. J. (2010a). Two Variations of the Public Good Index for Games with a Priori Unions. Control and Cybernetics, 39(3), 839-855.

Alonso-Meijide, J. M., Casas-Méndez, B., Fiestras-Janeiro, G., Holler, M. J. and Nohn, A. (2010b). Axiomatizations of Public Good Indices with a Priori Unions. Social Choice and Welfare, 35(3), 517-533.

Baldwin, R. and Widgrén, M. (2004). Winners and Losers under Various Dual Majority Rules in the EU's Council of Ministers. In Wiberg, M. (ed.), Reasoned Choices. Turku, The Finnish Political Science Association, 42-89.

Braham, M. (2005). Causation and the Measurement of Power. In Gambarelli, G. and Holler, M. J. (eds.), Power Measures III, Homo Oeconomicus, 22. Munich, AccedoVerlag, 645-653.

Braham, M. and van Hees, M. (2009). Degrees of Causation. Erkenntnis, 71, 323-344.

Ferrero, M. (ed.) (2004). The Rationale of Revolutions. Homo Oeconomicus, 21(2).

Goodin, R. (1998). Social Welfare as a Collective Social Responsibility. In Schmidtz, D. and Goodin, R. (eds.), Social Welfare and Individual Responsibility. Cambridge, Cambridge University Press, 97-195.

Holler, M. J. (1982). Forming Coalitions and Measuring Voting Power. Political Studies, 30, 262-271.

Holler, M. J. (2007). Freedom of Choice, Power, and the Responsibility of Decision Makers. In Josselin, J.-M. and Marciano, A. (eds.), Democracy, Freedom and Coercion: A Law and Economics Approach. Cheltenham, Edward Elgar, 22-45.

Holler, M. J. and Nohn, A. (2009). The Public Good Index with Threats in A Priori Unions. In Holler, M.J. (ed.), Essays in Honor of Hannu Nurmi, Homo Oeconomicus, 26. Munich, Accedo-Verlag, 393-401.

Holler, M. J. and Packel, E. W. (1983). Power, Luck and the Right Index. Zeitschrift für Nationalkonomie (Journal of Economics), 43, 21-29.

Johnson, P., Mayrand, K., Paquin, M. (2006). Governing Global Desertification: Linking Environmental Degradation, Poverty and Participation. Aldershot, Ashgate Publishing.

King, P. (2006). What Do We Mean by Responsibility? The Case of UK Housing Benefit Reform. Journal of Housing and the Built Environment, 21, 111-125.

Klemisch-Ahlert, M. (1993). Freedom of Choice: A Comparison of Different Rankings of Opportunity Sets. Social Choice and Welfare, 10, 189-207. 
Owen, G. (1977). Values of Games with a Priori Unions. In Hein, R. and Moeschlin, O. (eds.), Essays in Mathematical Economics and Game Theory. Berlin, Springer-Verlag, 76-88.

Pattanaik, P. K. and Xu, Y. (1990). On Ranking Opportunity Sets in Terms of Freedom of Choice. Recherches Economiques de Louvain, 56, 383-90.

Timoshenko, A. (2003). Environmental Negotiator Handbook. The Hague, Kluwer Law International.

UNFCCC (2004). United Nations Framework Convention on Climate Change, The First Ten Years. Bonn, Information Services of the UNFCCC.

United Nations Framework Convention on Climate Change. http://unfccc.int/2860.php. United Nations Convention to Combat Desertification. http://www.unced.int/. 


\section{Appendix}

\section{A1. Annex I and Annex II countries, and developing countries}

Members if the UNFCCC are split into three groups:

(i) Annex I countries (industrialized countries);

(ii) Annex II countries (developed countries which pay some of the expenses of developing countries);

(iii) developing countries.

These are mostly developed countries, of which there are currently 41, including the European Community which is a party in its own right. Annex I countries were aiming to return their emissions by 2000 to 1990 levels. They also have to make regular reports on their implementation of the Convention-in particular, on the policies and measures they are taking and the impacts that these are having on emission trends, as well as on the amount of greenhouse gases released into the atmosphere. Annex II parties, an Annex I subset, are the 24 highly developed countries. In addition to reducing their own emissions, they are also required to financially and otherwise support the efforts of developing countries. Developing countries, like all parties to the Convention have general commitments to respond to climate change but they have fewer specific obligations and can also rely on external support. They are required to provide a general description of the steps taken or envisaged to implement the Convention and estimate emissions of greenhouse gases. Developing countries have no immediate restrictions under the UNFCCC. This serves three purposes:

(i) Avoids restrictions on growth because pollution is strongly linked to industrial growth, and developing economies can potentially grow very fast.

(ii) It means that they cannot sell emissions credits to industrialized nations to permit those nations to over-pollute.

(iii) They get money and technologies from the developed countries in Annex II.

Developing countries may apply to become Annex I countries when they are sufficiently developed.

Developing countries are not expected to implement their commitments under the Convention unless developed countries supply enough funding and technology, and responding to climate change often has lower priority than economic and social development and dealing with poverty.

Some opponents of the Convention argue that the split between Annex I and developing countries is unfair, and that both developing countries and developed countries 
need to reduce their emissions. Some countries claim that the costs of following the Convention requirements will stress their economy. ${ }^{13}$

\section{A1.1 Annex I countries}

Australia, Austria, Belarus, Belgium, Bulgaria, Canada, Croatia, Czech Republic, Denmark, Estonia, Finland, France, Germany, Greece, Hungary, Iceland, Ireland, Italy, Japan, Latvia, Liechtenstein, Lithuania, Luxembourg, Monaco, Netherlands, New Zealand, Norway, Poland, Portugal, Romania, Russian Federation, Slovakia, Slovenia, Spain, Sweden, Switzerland, Turkey, Ukraine, United Kingdom, United States of America (40 countries and separately the European Union)

\section{A1.2 Annex II countries}

Australia, Austria, Belgium, Canada, Denmark, Finland, France, Germany, Greece, Iceland, Ireland, Italy, Japan, Luxembourg, Netherlands, New Zealand, Norway, Portugal, Spain, Sweden, Switzerland, United Kingdom, United States of America (23 countries and separately the European Union)

13 This is one of the reasons why President Bush did not sign the Kyoto Protocol. 